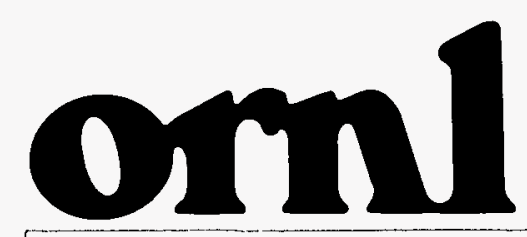

OAK RIDGE NATIONAL LABORATORY

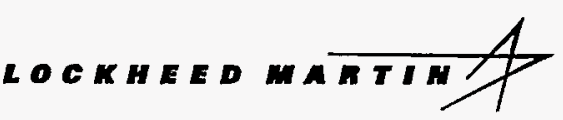$$
\text { I }
$$
LOCKHEED MARTIN ENERGY RESEARCH CORPORATION FOR THE UMTED STATES DEPARTMENT OF ENERGY ORNL-27 (3-06)
XRAYL: A Program for Producing Idealized Powder Diffraction Line Profiles from Overlapped Powder Patterns

\author{
C. R. Hubbard \\ B. Morosin \\ J. M. Stewart
}

RECEIVED

OCT 291996

OSTI

RERENVED

ort 2 y 1000

0011

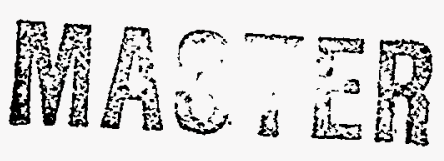


This report has been reproduced directly from the best available copy.

Available to DOE and DOE contractors from the Office of Scientific and Technical Information, P. O. Box 62, Oak Ridge, TN 37831; prices available from (423) 576-8401, FTS 626-8401.

Available to the public from the National Technical Information Service, U.S. Department of Commerce, 5285 Port Royal Road, Springfield. VA 22161.

This report was prepared as an account of work sponsored by an agency of the United States Government. Neither the United States Government nor any agency thereof, nor any of their employees, makes any warranty, express or implied, or assumes any legal liability or responsibility for the accuracy, completeness, or usefulness of any information, apparatus, product, or process disclosed, or represents that its use would not infringe privately owned rights. Reference herein to any specific commercial product, process, or service by trade name. trademark, manufacturer, or otherwise, does not necessarily constitute or imply its endorsement, recommendation, or favoring by the United States Government or any agency thereof. The views and opinions of authors expressed herein do not necessarily state or reflect those of the United States Government of any agency thereof. 
Metals and Ceramics Division

\section{XRAYL: A PROGRAM FOR PRODUCING IDEALIZED POWDER DIFFRACTION LINE PROFILES FROM OVERLAPPED POWDER DIFFRACTION PATTERNS}

C. R. Hubbard, B. Morosin, and J. M. Stewart

Date Published: September 1996

NOTICE: This document contains information of a preliminary nature. It is subject to revision or correction and therefore does not represent a final report.

Prepared for

U.S. Department of Energy

Assistant Secretary for Energy Efficiency and Renewable Energy

Office of Transportation Technologies

EE 5104000

Prepared by the

OAK RIDGE NATIONAL LABORATORY

Oak Ridge, Tennessee 37831-6285

managed by

LOCKHEED MARTIN ENERGY RESEARCH CORPORATION

for the

U.S. DEPARTMENT OF ENERGY

under contract DE-AC05-960R22464

and, in part, under DE-AC04-94AL85000 at SNL 


\section{DISCLAIMER}

Portions of this document may be illegible in electronic image products. Images are produced from the best available original document. 


\section{CONTENTS}

Page

LIST OF FIGURES $\ldots \ldots \ldots \ldots \ldots \ldots \ldots \ldots \ldots \ldots \ldots \ldots \ldots \ldots \ldots \ldots \ldots \ldots$

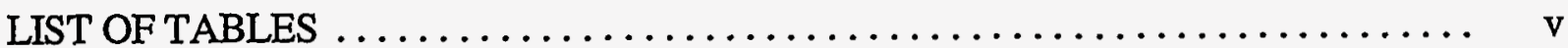

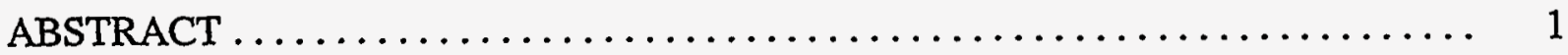

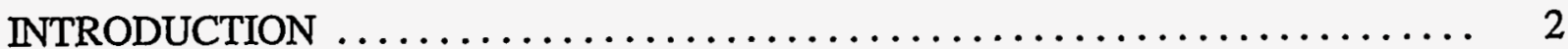

CLASSIC FITTING FUNCTIONS $\ldots \ldots \ldots \ldots \ldots \ldots \ldots \ldots \ldots \ldots \ldots \ldots \ldots \ldots$

OVERVIEW OF PROCESSING AND FILE USE BY XRAYL $\ldots \ldots \ldots \ldots \ldots \ldots \ldots$

OPTIONAL FILES FOR ESTIMATING ERRORS IN CRYSTALLITE

SIZE AND STRAIN $\ldots \ldots \ldots \ldots \ldots \ldots \ldots \ldots \ldots \ldots \ldots \ldots \ldots \ldots \ldots$

USING THE PROGRAM XRAYL $\ldots \ldots \ldots \ldots \ldots \ldots \ldots \ldots \ldots \ldots \ldots \ldots \ldots$

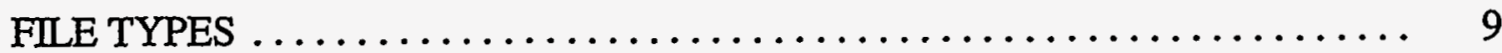

STRUCTURE OF THE .XIN FILE $\ldots \ldots \ldots \ldots \ldots \ldots \ldots \ldots \ldots \ldots \ldots \ldots \ldots \ldots \ldots$

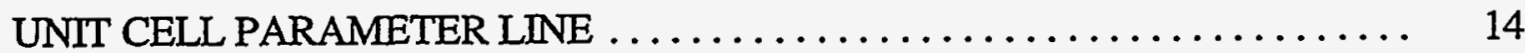

WAVE LENGTH AND GENERAL REFINEMENT CONTROL LINE . . . . . . . . 14

INDIVIDUAL WINDOW INSTRUCTION LINES . . . . . . . . . . . . . . 14

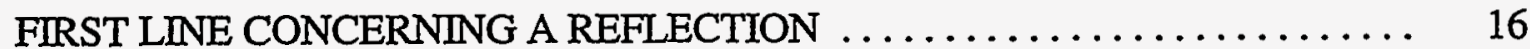

SECOND LINE CONCERNING A REFLECTION $\ldots \ldots \ldots \ldots \ldots \ldots \ldots \ldots \ldots \ldots$

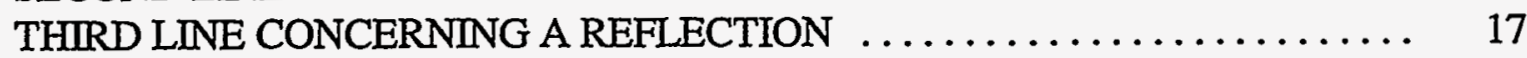

WINDOWS, REFLECTIONS, AND INPUT DATA ORDER -

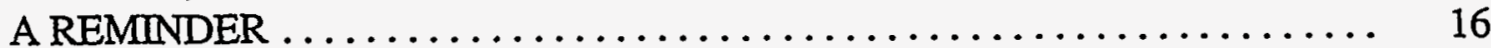

LINE TO TERMINATE A .XIN FILE ....................... 18

EXAMPLE OF A .XIN FULE ........................... 19

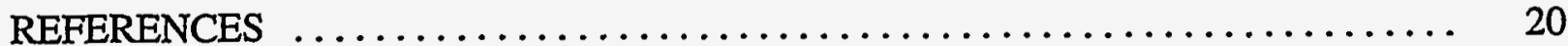

APPENDIX A - Format of the <identity>.DA and <identity $>$.IDL files . . . . . . 21

APPENDIX B - Auxiliary programs to support XRAYL $\ldots \ldots \ldots \ldots \ldots \ldots \ldots$

APPENDIX C - History of the authorship of programs XRAYL, POWTES, and

CRYSIZ 
APPENDIX D - Symbolic "decks" and their implementation $\ldots \ldots \ldots \ldots \ldots \ldots \ldots .27$

APPENDIX E - Example runs for testing XRAYL $\ldots \ldots \ldots \ldots \ldots \ldots \ldots \ldots .29$

APPENDIX F - Source code and example diskettes $\ldots \ldots \ldots \ldots \ldots \ldots \ldots \ldots \ldots . \quad 37$ 


\section{LIST OF FIGURES}

Figure

Page

E.1 Raw data from POWLAP, fitted data from XRAYL, and difference in raw and fitted intensity $\ldots \ldots \ldots \ldots \ldots \ldots \ldots \ldots \ldots \ldots \ldots \ldots \ldots \ldots \ldots \ldots \ldots \ldots$

E.2 Same plot as for Fig. E.1, but for the broadened data $\ldots \ldots \ldots \ldots \ldots \ldots \ldots$

E.3 Two reference profiles extracted by XRAYL, superimposed on one plot $\ldots \ldots \ldots 33$

E.4 Broadened profiles plotted as in Fig. E. $3 \ldots \ldots \ldots \ldots \ldots \ldots \ldots \ldots \ldots \ldots$

E.5 Plot of real data taken for shock-modified sample of zirconia $\ldots \ldots \ldots \ldots$

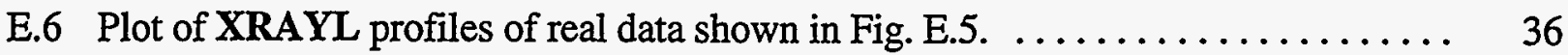

\section{LIST OF TABLES}

Table

1 Fitting functions implemented in XRAYL $\ldots \ldots \ldots \ldots \ldots \ldots \ldots \ldots \ldots \ldots \ldots$

E.1 Purpose of files on disk, where they are created, and where they are used $\ldots \ldots \ldots \quad 30$ 


\title{
XRAYL: A PROGRAM FOR PRODUCING IDEALIZED POWDER DIFFRACTION LINE PROFILES FROM OVERLAPPED POWDER DIFFRACTION PATTERNS ${ }^{*}$
}

\author{
C. R. Hubbard, B. Morosin, ${ }^{\dagger}$ and J. M. Stewart ${ }^{\ddagger}$
}

\begin{abstract}
The X-ray diffraction patterns of samples of polycrystalline materials are used to identify and characterize phases. Very often the total (or composite) profile consists of a series of overlapping profiles. In many applications it is necessary to separate the component profiles from the total profile. (In this document the terms profile, line, and peak are used interchangeably to represent these features of X-ray or neutron diffraction patterns.) A computer program, XRAYL, first developed in the 1980s and subsequently enlarged and improved, allows the fitting of analytical functions to powder diffraction lines. The fitting process produces parameters of chosen profile functions, diffraction line by diffraction line. The resulting function parameters may then be used to generate "idealized" powder diffraction lines as counts at steps in $2 \theta$. The generated lines are effectively free of statistical noise and contributions from overlapping lines. Each separated line extends to background on both sides of the generated profile. XRAYL may, therefore, be used in X-ray powder diffraction profile analysis as a preprocessor program, that is, separating peaks and feeding the "resolved" data to subsequent analysis programs. This self-contained document includes: (1) a description of the fitting functions coded into XRAYL, (2) an outline of the least-squares algorithm used in fitting the profile function, (3) the file formats and contents utilized by the computer code, (4) the user options and their presentation requirements for execution of the program, (5) an example of input and output for a test case, and (6) source code listings on a diskette.
\end{abstract}

"Research sponsored by the U.S. Department of Energy, Assistant Secretary for Energy Efficiency and Renewable Energy, Office of Transportation Technologies, as part of the High Temperature Materials Laboratory User Program, under contracts DE-AC05-960R22464 with Lockheed Martin Energy Research Corporation and, in part, DE-AC04-94AL85000 (at Sandia National Laboratories).

†Sandia National Laboratories, Albuquerque, NM 87185-1421.

‡University of Maryland, College Park, MD 20742. 


\section{INTRODUCTION}

$\mathrm{X}$-ray powder diffraction is a widely used method for identifying and characterizing polycrystalline phases of materials. The diffraction pattern of polycrystalline materials consists of a slowly varying background and a number of narrow lines (profiles) whose positions are determined by the unit cell parameters of the crystalline phase. For powders of crystals of small unit cell size, less than $\sim 3 \mathrm{~nm}$, high symmetry, and made up of crystallites at least $200 \mathrm{~nm}$ in size, the diffraction lines are well separated and can be individually measured. However, as the cell symmetry is reduced and the cell size is increased, or if the radiation is not monochromatic, more lines are observed, and many lines overlap. The shape of a diffraction line profile is a convolution of the instrumental effects, including monochromatization, instrumental alignment, and microstructure of the specimen. The shape of the profiles due to microstructure serves as a basis for establishing crystallite size and root mean square (rms) residual lattice strain. One of the major goals of program XRAYL ${ }^{1}$ is to separate the individual diffraction lines from the overlapping total pattern and to present these separated line profiles for further analysis.

Examples of applications requiring separated lines include measurement of accurate line positions for unit cell parameter determination, line intensity for quantitative phase and texture analysis, and line profile shape for crystallite size and residual microstrain analysis. The profile fitting technique ${ }^{2,3}$ is effective for decomposing overlapping reflections into individual component profiles without prior knowledge about the crystal structure of the material. However, profile fitting cannot be applied unless certain specific functions are assumed to characterize the line profiles. A few analytical functions have been reported ${ }^{46}$ to represent adequately the shape of a real powder diffraction line. In XRAYL the fitting functions which may be chosen for each specified profile are: Lorentzian, Gaussian, Voigt, Pearson VII, or Rational Polynomial.

In contrast to the line-separating strategy employed in a program like XRAYL is the method of Rietveld. ${ }^{7,8}$ Rietveld's method fits the whole powder pattern at once as opposed to separating out the individual line profiles, reflection by reflection. This method overcomes most of the limitations in obtaining crystal structure information from raw powder diffraction data. It 
has become widely used when large enough single crystals of a phase are unobtainable. In the Rietveld method, a complete pattern over the whole range of $2 \theta$ is collected and analyzed. The typical analysis involves fitting a functional representation of the instrumental breadth, ${ }^{9}$ a slowly varying background, atomic positions, atomic thermal parameters, and, in defect structures, a site occupancy. In some cases, Rietveld analysis is used for quantitative analysis of multiphase samples (usually two-phase samples). Occasionally, microstructural parameters, such as rms coherent domain size and mean residual microstress, are also included in the fitting process.

Both the individual profile fitting and the Rietveld method resolve difficulties concerning statistical noise in the intensity data, determination of background intensity, separation of complex patterns due to large unit cell size or a low-symmetry crystal system, and resolution of overlapping lines due to multiple phases. The individual line profile method, however, provides the best means of determining microstructure. In many materials the microstructure is quite anisotropic. In this case the Rietveld analysis can provide only limited information ${ }^{10}$ compared to the individual profile fitting methods. The approach of fitting individual profile patterns provides several important additional benefits for analyzing microstructure, namely elimination of truncation errors and freedom to choose the data collection range at will.

To date, XRAYL has been used to analyze selected diffraction regions and to write the "resolved" data for use by CRYSIZ, a program for analyzing crystallite size and rms residual microstrain in polycrystalline materials. CRYSIZ is described in detail in ORNL/TM-13273. When broadened and reference profile data sets are to be processed by XRAYL, they may be analyzed in the same computer run, not in two separate runs. Analyzing the two data files within a single run provides the program the information needed to prepare the generated data files with identical $2 \theta$ range and step size. In addition, the profiles will be centered on the same $2 \theta$ so that Fourier deconvolution of the pair of observations will be meaningful. The program resolves any differences in step size or range in the raw data supplied. The program cannot be used in a completely automatic way. It requires careful inspection of the output results to confirm that the fitting makes physical sense.

This self-contained document includes: (1) description of the classical fitting functions coded into XRAYL, (2) an overview of the least-squares processing algorithm used in fitting the 
profile function, (3) the user options and their presentation requirements for execution of the program, (4) the file types and their formats and contents required for running the computer code, (5) examples, in Appendices E and F, of input and output for a test case, and (6) source code listings on a diskette.

\section{CLASSIC FITTING FUNCTIONS}

The analysis of $\mathrm{X}$-ray powder diffraction profiles by fitting individual profiles requires "clean" patterns free of random noise and separated with respect to overlapping lines and mixed phases. In order to accomplish the production of clean patterns, it is often necessary to have sharp "reference" patterns to be used in conjunction with mixed-phase or "broadened" reflection diffraction profiles. When the patterns produced by samples to be tested are completely resolved, that is, none of the profiles are overlapped, the necessary analysis calculations may be done without the aid of a program like XRAYL. However, in practice, most diffraction patterns present serious overlap between adjacent reflections. The overlap becomes more severe in materials with low symmetry and large unit cells. There may also be present other substances, contaminants, the lines of which must be dealt with in an appropriate manner. For example, even a small amount of overlap in the pattern will produce serious errors in the computation of size and strain parameters. XRAYL extracts individual, filtered, reflection profiles from raw powder diffraction data by fitting mathematical functions to the data by a least-squares procedure.

In powder diffraction, the most useful profile functions are those that can be applied over the entire angular range of data collection. ${ }^{2,3}$ The profile parameters of these functions must include angle-dependent breadth and shape parameters. Ideally, the profile parameters should be easily interpreted by the user and should change slowly as a function of the scattering angle. The breadth and shape parameters should accurately account for profile asymmetry. A readily interpreted measure of breadth is the full width at half maximum (FWHM). In the functions programmed, FWHM is chosen when feasible as a fitted parameter. In addition, parameters for peak position, peak maximum, background, background slope, and ratio of $\mathrm{K} \alpha_{1}$ to $\mathrm{K} \alpha_{2}$, if 
present, must be used. Asymmetry is dealt with by permitting separate parameters for the high and low $2 \theta$ sides of each profile.

It would be desirable to select profile functions based on the convolution of each component which contributes to line broadening. ${ }^{11}$ Unfortunately, no theoretical parametric representation for the convolution has been put forward. Therefore, representation of a diffraction profile is accomplished by the use of well-known mathematical functions. This is the best compromise that can be made in the absence of the "true" function and the physical justification it would provide. The functions used are detailed in what follows.

Table 1 summarizes the implemented functions. ${ }^{4-6}$ In the equations, the quantity $\mathrm{x}$ is the difference between the $2 \theta$ of the generated function and the $2 \theta_{0}$ of the observed peak center:

$$
x=\left(2 \theta-2 \theta_{0}\right)
$$

The forms of the Lorentzian, Gaussian, and Pearson VII functions implemented in XRAYL are expressed in terms of the FWHM of the peak. In Table 1 the symbol $\gamma$ is used for FWHM with a subscript $G, L$, or $P$ to designate the function used to determine it. The benefit of expressing these profile functions in terms of FWHM is that the starting values for least squares may be easily obtained, and the refined parameters are readily interpreted by the user. In all functions the parameter $S$ is used for normalization scaling. The fitting parameters in the Voigt and Rational functions do not have an easily seen relationship to the FWHM. In these functions the FWHM is determined by an analysis of the generated profile. For background material on the applications and limitations of these functions, a summary may be found in the thesis of Y. Zhang and the references cited therein. ${ }^{12}$

In order to model the asymmetric nature of powder diffraction profiles, split functions are used in XRAYL. The same functional form is used for both sides of the peak, but independent shape parameters are refined. For the split function the left and right sides share the same peak maximum and peak position. The FWHM used in the scaling for the split function is taken as the arithmetic mean of the left and right FWHM parameters. Left and right refer to the low and high $2 \theta$ sides of the profile. 
Table 1. Fitting functions implemented in XRAYL

\begin{tabular}{|c|c|c|c|}
\hline Function & $\begin{array}{c}\text { Typical } \\
\text { notation }\end{array}$ & $\begin{array}{c}\text { Notation of } \\
\text { implementation }\end{array}$ & $\begin{array}{c}\text { Parameters } \\
\text { fitted }\end{array}$ \\
\hline Lorentzian & $\frac{S}{\left(1+k x^{2}\right)}$ & $2 \frac{S}{\pi \gamma_{L}} *\left(\frac{1}{1+\frac{4 x^{2}}{\gamma_{L}^{2}}}\right)$ & $\begin{array}{l}S \\
\gamma_{L}\end{array}$ \\
\hline Gaussian & $S * \exp \left(\frac{-x^{2}}{k^{2}}\right)$ & $S * \frac{\sqrt{(4 \ln 2)}}{\sqrt{\pi} * \gamma_{G}} \exp \left[-4 \ln 2 *\left(\frac{x}{\gamma_{G}}\right)^{2}\right]$ & $\begin{array}{l}S \\
\gamma_{G}\end{array}$ \\
\hline Voigt & As implemented & $\begin{array}{c}S * R e[\omega(z)] \\
\omega(z)=\exp \left(-z^{2}\right) \operatorname{erfc}(-i z) \\
z=\alpha+i \beta \\
\alpha=2(\ln 2)^{1 / 2} *\left(\frac{x}{\gamma_{G}}\right) \\
\beta=(\ln 2)^{1 / 2} *\left(\frac{\gamma_{L}}{\gamma_{G}}\right)\end{array}$ & $\begin{array}{l}S \\
\alpha \\
\beta\end{array}$ \\
\hline Pearson VII & $S *\left(1+\frac{x^{2}}{m k^{2}}\right)^{-m}$ & $\frac{2 * \Gamma(m) * S}{\sqrt{\pi} * \Gamma(m-0.5) * \gamma_{P}} *\left(1+\frac{4 x^{2}}{\gamma_{P}^{2}}\right)^{-m}$ & $\begin{array}{l}S \\
\mathrm{~m} \\
\gamma_{\mathrm{P}}\end{array}$ \\
\hline Rational & $\frac{S}{1+A x^{2}+B x^{4}}$ & Same as typical notation & $\begin{array}{l}\text { S } \\
\text { A } \\
\text { B }\end{array}$ \\
\hline
\end{tabular}


In addition to the parameters defined above, several other fitting parameters are typically required. The linear background, $b$, with a possible slope, $m$; the scaling factor, $\mathrm{S}$; and the intensity ratio, $R$, between $K \alpha_{1}$ and $K \alpha_{2}$ may also be included in the fitting process. $S$ is the scale factor that returns the normalized peak to the intensity of the input peak, one per profile; $x$ is defined above; $\mathrm{Y}(\mathrm{x})$ is the value of the fitting function at $\mathrm{x} ; \mathrm{b}$ is the background intensity at low $2 \theta$; $m$ is the slope in the background as a function of steps in $2 \theta$; and $\Delta(2 \theta)$ is the scan-step size. This results in the calculated intensity as a function of $2 \theta$ being represented by the sum over all the steps of the contribution to intensity of all overlapped profiles in the scan "window":

$$
I_{c a l}\left(2 \theta_{i}\right)=b+m(i-1) * \Delta(2 \theta)+\Sigma S * R * Y\left(2 \theta_{i}-2 \theta_{0}\right) \text {. }
$$

\section{OVERVIEW OF PROCESSING AND FILE USE BY XRAYL}

The XRAYL program is designed to operate on "windows" in $2 \theta$, that is, on regions in $2 \theta$ space. The program allows up to five profiles per window. As shown above there are two types of fitting parameters. The "regional" parameters are the background parameters and the ratio of $\mathrm{K} \alpha_{1}$ to $\mathrm{K} \alpha_{2}$. The "profile" parameters depend on the fitting function chosen. The initial value of all parameters may be set by default or specified in input. Every parameter may either be refined or held constant.

The program reads either one or two intensity data files. The first file is called the "reference" file and is used to establish values for an unbroadened diffraction pattern. The second file is called the "broadened" file and contains data for a sample to be analyzed. If precise values of $2 \theta$ for the center of the broadened profiles are supplied, the reference file may not be needed. This would come about if no reference pattern was available, and/or it was deemed necessary to do further calculations on the broadened patterns. Either way the patterns are fitted to specified functions by a least-squares procedure.

Once the least-squares procedure has converged, the parameters of the refinement are used to generate output files containing calculated intensity data. Lines, such as $\mathrm{K} \alpha_{2}$ or impurities, 
may be omitted from the profiles in the output files. Profiles of overlapped peaks are written as separate records corresponding to completely resolved patterns. A specific application of these separated peaks is to permit their use in the analysis of crystallite size and residual strain.

Carefully screened data with constant $a_{3}$ values (regions of $1 / d$ space) may be generated in which overlapping lines have been removed and the raw data have been smoothed. ${ }^{13}$ A supplementary file is written which contains the refined parameters of the profiles. It may be used to regenerate profiles or edited to generate a pseudo reference pattern for samples for which no measured reference pattern is available.

The estimates of the errors of the refined profile parameters are obtained from the Jacobian matrix produced by the least-squares procedure. ${ }^{14}$ As an overall evaluation of the fitting, two quantities are calculated. One is called the correlation of fit (COF), which is defined as follows:

$$
C O F=\frac{\Sigma\left(I_{o b s}-I_{a v e}\right)^{2}-\Sigma\left(I_{o b s}-I_{c a l}\right)^{2}}{\Sigma\left(I_{o b s}-I_{a v e}\right)^{2}}
$$

where $I_{\text {obs }}, I_{\text {ave }}$, and $I_{\text {cal }}$ are the observed, average, and calculated intensities, respectively. For a perfect fit $\mathrm{COF}=1$, and for a random fit $\mathrm{COF}=0$. The other measure of fit is the conventional crystallographic " $R$ " value:

$$
R=\left\{\frac{\Sigma\left(I_{o b s}-I_{c a l}\right)^{2}}{\Sigma I_{o b s}^{2}}\right\}^{1 / 2}
$$

\section{OPTIONAL FILES FOR ESTIMATING ERRORS IN CRYSTALLITE SIZE AND STRAIN}

Two additional files of the resolved lines may be written. These consist of profiles altered by a chosen number of standard deviations of the fitting parameters. These files will permit the recalculation of quantities based on the shape of the profiles by using profiles numerically altered 
from the best least-squares fit. This permits use of a numerical method to estimate the limit of error in the parameters derived from the use of the idealized profiles such as crystallite size and strain. This is tantamount to calculating a numerical differential to establish an error estimate. One uses the best-fit pattern and the patterns distorted by n $\sigma$ in subsequent calculations. The value $\sigma$, the least-squares estimated standard deviation of the profile parameters, may be multiplied by $\mathrm{n}$, a factor chosen to offset the parameters. The difference in the results gives a measure of the uncertainty in calculated values derived from the profiles. None of these additional calculations is automated. The result must be obtained by additional runs of the analysis program using, in turn, the distorted files in place of the "best" file.

\section{USING THE PROGRAM XRAYL}

The XRAYL program will open and process a number of prepared files and produce output files in the process. Each file type is defined by an "extehsion" mnemonic following a period. Before the period an 11-character code, here referred to as the <identity >, may be prefixed. The $<$ identity > code should be mnemonic of the data set being treated. The extension codes are fixed by the program while the identity is chosen by the user. For some computers or operating systems, such as disk operation system (DOS) for a personal computer (PC), it may not be possible to use all 11 characters. In fact, for DOS the limit will be only four characters.

\section{FILE TYPES}

\begin{tabular}{|l|l|}
\hline .XIN & $\begin{array}{l}\text { Program input instruction file. Program may be run interactively to supply the } \\
\text { information contained in a .XIN file, but the creation, beforehand, of this file by a local } \\
\text { line editor is much more productive. }\end{array}$ \\
\hline .DA & $\begin{array}{l}\text { Raw observed intensity data input files. Usually one for reference profiles and one for } \\
\text { broadened profiles. Covers a "window" of } 2 \theta \text { containing up to five reflection profiles. } \\
\text { See Appendix A for format. }\end{array}$ \\
\hline .XPN & Output file containing summary of run suitable for printing. \\
\hline
\end{tabular}




\begin{tabular}{|l|l|}
\hline .XPL & Optional output file containing crude line printer plots for inspection. \\
\hline .XEX & Optional output file containing raw plot data for use with local plotting software. \\
\hline .IDL & Output files containing the separated, idealized output profiles. \\
\hline .WM & $\begin{array}{l}\text { Optional output files like .IDL but with least-squares parameters displaced by a } \\
\text { specified number of standard deviations down from the best result. }\end{array}$ \\
\hline .IDP & Optional output file like .IDL but with the parameters displaced up. \\
\hline .FIT & $\begin{array}{l}\text { Optional output file containing the refined least-squares parameters of fit for each } \\
\text { processed profile. }\end{array}$ \\
\hline
\end{tabular}

In order to use the program XRAYL, it is usually necessary to have two input files: one with the reference data, and one with the broadened data. These files must both scan the same regions of $2 \theta$ in "windows." There may be up to five unique reflections in each window. The files will be "opened" if they have the designation <identity>.DA, where <identity $1>$ and $<$ identity2> are the names chosen by the user for the data sets (for example: NaClrf.DA for the reference pattern and $\mathrm{NaClb}$.DA for broadened sample 1). The contents and structure of these ASCII files are given in Appendix A. Within the ASCII files themselves there is a 53-character, user-provided "title" which should be used to futher identify the sample. The up-to-53 character title will be formed from information supplied by interactive response at the start of progam execution.

In addition to the data files, information concerning the instructions for the run must be given. These may be given interactively, or more conveniently, by preparation of an <identity >XIN file. Whichever method is chosen, the options to be specified concern which method of fitting is to be carried out, the indices and $2 \theta$ of each reflection, the plots to be generated, the extent of the printed details, and the reflections to be placed in the output.IDL files. In the interactive mode the options are presented as a set of tedious questions to be answered in turn. It is crucial for the user to recognize that the program depends on the values of $2 \theta$ given in the 'HKL_2TH_SHP' input line. The least-squares refinement requires a value within its convergence "circle." If the values given are too far from the profile maximum, or if there is serious overlap with adjacent profiles, the program may fail during the refinement. A 
reasonable strategy to employ is to use the reference pattern alone, assuming that it is resolved, to establish the values of $2 \theta$ for each reflection. Then make a separate run for the broadened sample, fixing the value of $2 \theta$ for the broadened reflections at the refined values of their reference counterparts. To be successful, complicated patterns may require two iterations in which the values of $2 \theta$ given in the 'HKL_2TH_SHP' lines are reset by the user. The result of a "bad" starting $2 \theta$ can be anything from the coalescence of two profiles, to a detected problem which produces a diagnostic message, to a divide overflow in the least-squares routines. All divisions in the program outside the Slatec package of matrix manipulation routines are "protected." Those inside are not. It may also be found that if one function will not refine properly, another will. If Pearson-VII fails Gaussian may well work.

\section{STRUCTURE OF THE .XIN FUE}

This file, which specifies the calculations to be done and the results to be displayed, must consist of a series of "free format lines" which are parsed into fields separated by blanks (spaces). Note that the first field is alphanumeric. Therefore, the "string" must be set off with single quote marks. These lines may be prepared by means of a line editor and then used repeatedly to drive the program. The lines and the order in which they must be supplied in the file are:

\section{Unit cell parameter line:}

'CELL_PARAMET' (one per .XIN file)

Wavelength and general refinement control line:

'WAV_LEN_REFN' (one per.XIN file)

Window instruction lines:

'REGIN_2_THET' (one per window)

Three lines for each reflection in the window:

'HKL_2THT_SHP'

'SIG_PARM_REF' 


\section{'NUM_ERR_GENR'}

(one set for each reflection in window)

Repeating, if necessary, at least four lines for each subsequent window:

'REGIN_2_THET' (one per subsequent window)

Three lines for each reflection in the window:

'HKL_2THT_SHP'

'SIG_PARM_REF'

'NUM_ERR_GENR'

(one set for each reflection in subsequent window)

One line that marks the end of the whole.XIN file:

'REGIN_2_THET' -1

Lines of every type are mandatory, the numbers required being determined by the nature of the input data. An example of a .XIN file is shown on page 15. In this example there is just one reflection per window. The benefit of using a .XIN file is that it may be edited with the local line editor for use with other problems or samples or to update and fix parameters such as $2 \theta$. It is important to note that since these input lines are "free format," every field must be given a value; none may be left "blank." In some cases, which are specified below, the use of a negative number or zero in certain fields will cause default values, stored in the program, to be used. The term "free format" is used to designate that the input to a .XIN file is read in "fields." Each field consists of a string of contiguous non-blank characters separated by one or more blank characters. Therefore, any of the three lines following are read, "parsed," into the program with identical results:

'CELL_PARAMET' 0.18410 .18410 .18410 .00 .00 .0

$\begin{array}{lllllll}\text { 'CELL_PARAMET' } & 0.1841 & 0.1841 & 0.1841 & 0.0 & 0.0 & 0.0\end{array}$ $\begin{array}{lllllll}\text { 'CELL_PARAMET' } & .1841 & .1841 & .1841 & 0 & 0 & 0\end{array}$ 
The important thing to remember is that the free format reading algorithm tolerates additional spaces and equivalent representations for numbers but cannot tolerate missing fields or unquoted character strings.

In the case of the diffractometer and XRAYL data files (.DA, .IDL, .IDM, and .IDP), however, the format is fixed. Every character is assigned a "column" position following the rules of FORTRAN format statements. These data file formats are given in Appendix A. The preparation of these data files requires some planning. The gathering of the original diffraction data will usually be based on the narrowest peak to be measured and the diffracting power of the reflections to be measured. The $2 \theta$ step size should be set so that at least 20 measurements are made across each profile. The step size will generally be dictated by the reference pattern. It is important that scans be wide enough that background is reached on both sides. It is this requirement that resulted in XRAYL being coded in terms of "windows." It is very often the case with broadened profiles that several reflections overlap so that a wide, inclusive, scan must be made to reach background. Therefore, the scan widths for each window will be dictated by the broadened pattern. The counting time at each point must be sufficient to ensure high reliability, i.e., good counting statistics, in the profile regions. The time required will depend upon the nature of the sample and the source intensity of the diffractometer. If the X-ray source is weak, or if the sample is small or a poor diffractor, the counting times will have to be long in order to produce data that will be good enough to be fitted reliably by one of the functions in XRAYL. The counting times for the reference and broadened patterns may vary. The requirement is that each window have data that can be distinguished from background in the peak regions. The $2 \theta$ order of the instructions given in the .XIN file must be the same as the data in the .DA file. 
UNIT CELL PARAMETER LINE

\begin{tabular}{|l|l|}
\hline Field & Contents \\
\hline 1 & 'CELL_PARAMET' \\
\hline 2 & Reciprocal cell dimension $\mathrm{a}^{*}$ \\
\hline 3 & Reciprocal cell dimension $\mathrm{b}^{*}$ \\
\hline 4 & Reciprocal cell dimension $\mathrm{c}^{*}$ \\
\hline 5 & Reciprocal cell angle as $\cos \left(\alpha^{*}\right)$ \\
\hline 6 & Reciprocal cell angle as $\cos \left(\beta^{*}\right)$ \\
\hline 7 & Reciprocal cell angle as $\cos \left(\gamma^{*}\right)$ \\
\hline
\end{tabular}

WAVE LENGTH AND GENERAL REFINEMENT CONTROL LINE

\begin{tabular}{|l|l|}
\hline Field & Contents \\
\hline 1 & 'WAV_LEN_REFN' \\
\hline 2 & Wave length $\mathrm{K} \alpha_{1}$ Angstroms (-1 defaults to $\mathrm{Cu} \mathrm{K} \alpha_{1} 1.54051 \AA$ ) \\
\hline 3 & Relative intensity of $\mathrm{K} \alpha_{1}(-1$ defaults to 1.0$)$ \\
\hline 4 & Wave length of $\mathrm{K} \alpha_{2}$ Angstroms (-1 defaults to $\left.\mathrm{Cu} \mathrm{K} \alpha_{2} 1.54433 \AA\right)$ \\
\hline 5 & Relative intensity of $\mathrm{K} \alpha_{2}(-1$ defaults to 0.5$)$ \\
\hline 6 & $\begin{array}{l}\text { 'Y'/'N' for retain/remove } \mathrm{K} \alpha_{2} \text { lines (if y, weights from fields } 3 \text { \& } 5 \text { above will be } \\
\text { used) }\end{array}$ \\
\hline 7 & $\begin{array}{l}\text { The first convergence criterion for least squares. The number of significant digits to } \\
\text { which two successive cycles agree. (0 defaults to } 5)\end{array}$ \\
\hline 8 & $\begin{array}{l}\text { The second convergence criterion for least squares. If, on two successive cycles, the } \\
\text { residual sum of squares estimate shows a relative difference less than or equal to this } \\
\text { number, then convergence is assumed. (0 defaults to } 0.0001)\end{array}$ \\
\hline 9 & $\begin{array}{l}\text { The third convergence criterion for least squares. A number which is the maximum } \\
\text { (Euclidian) norm of the approximate gradient. (0 defaults to } 0.0)\end{array}$ \\
\hline 10 & O/1 for single/multiple output files to be generated. \\
\hline
\end{tabular}

\section{INDIVIDUAL WINDOW INSTRUCTION LINES}

There must be one line of this type for each window of $2 \theta$ to be filtered. Each line of this type will require three additional lines, in the order of encounter, for each reflection in the 
window. Thus, beginning at line three of an <identity $>$.XIN file will be placed groups of lines that provide information and instructions for the least-squares profile fitting to be done.

\begin{tabular}{|l|l|}
\hline Field & Contents \\
\hline 1 & REGIN_2_THET' \\
\hline 2 & $\begin{array}{l}\text { The number of reflections in the } 2 \theta \text { window. This establishes the number of three- } \\
\text { line groups, one group per reflection, which must follow this line. }\end{array}$ \\
\hline 3 & $\begin{array}{l}\text { Fitting function as: } \\
1 / 2 / 3 / 4 / 5 \text { for Lorentz/Gaussian/Voigt/Pearson VII/Rational Polynomial }\end{array}$ \\
\hline 4 & $0 / 1$ to indicate symmetrical/split function \\
\hline 5 & $\begin{array}{l}\text { 0/1 one/two .DA input files. Choice } 1 \text { would be used for a "reference" and } \\
\text { "broadened" pair. }\end{array}$ \\
\hline 6 & $\begin{array}{l}\text { Number of points at each end of the window to be used to establish the background } \\
\text { intensity. Both background magnitude and slope will be established from these } \\
\text { points. Only the number of points specified in this field will be used for background. }\end{array}$ \\
\hline 7 & $\begin{array}{l}0 / 1 \text { for remove/restore the background in the idealized output lines. This option } \\
\text { allows the original background to be restored to the filtered, separated profiles. }\end{array}$ \\
\hline 8 & $\begin{array}{l}\text { The period or spread in Angstroms of the idealized output data, } a_{3} . \text { The value of } a_{3} \\
\text { sets the } 1 / d \text { scan range in the separated profiles. If the } a_{3} \text { supplied here is outside the } \\
\text { range of } 100.0 \text { to } 15.0, \text { then the minimum value of } a_{3} \text { in the experimental input data } \\
\text { will be used. }\end{array}$ \\
\hline 9 & $2 \theta$ step size for the output profiles; 0 is set to 0.005 degrees. \\
\hline 10 & $\begin{array}{l}\text { Plotting as } 0 / 1 / 2 / 3 / 4 \text { for no/fitted profiles/fitted profiles reflection by reflection/raw } \\
\text { data profiles/all of the profiles. }\end{array}$ \\
\hline 11 & $0 / 1$ for do not/do refine the background intensity. \\
\hline 12 & $0 / 1$ for do not/do refine the background slope. \\
\hline 13 & $0 / 1$ for do not/do refine the intensity ratio of K $\alpha_{1}$ and K $\alpha_{2}$ profiles. \\
\hline 14 & $\begin{array}{l}\text { 'N'/'Y' for do not/do weight the least-squares refinement by the counting statistics. } \\
\text { In general, a weighted refinement is recommended. However, in the case where the } \\
\text { intensities of the profiles to be separated are greatly different, the refinement should } \\
\text { not be weighted. }\end{array}$ \\
\hline
\end{tabular}


FIRST LINE CONCERNING A REFLECTION

\begin{tabular}{|c|c|}
\hline Field & Contents \\
\hline 1 & 'HKL_2THT_SHP' \\
\hline 2 & $h$ index of the reflection \\
\hline 3 & $k$ index of the reflection \\
\hline 4 & $l$ index of the reflection \\
\hline 5 & $\begin{array}{l}2 \theta \text { of } \mathrm{K} \alpha_{1} \text { of the reflection, in degrees. If set to } 0.0 \text { degrees, the actual value will be } \\
\text { calculated from the cell parameters and the Miller indices given above. The ability } \\
\text { to supply a } 2 \theta \text { angle permits treatment of lines which arise from other phases. } \\
\text { WARNING: The values of } 2 \theta \text { given or calculated must be very close to the actual } \\
\text { peak positions in the diffraction pattern file. If this condition is not met, the least- } \\
\text { squares procedure may fail to converge. The } 2 \theta \text { value refined from the peaks in the } \\
\text { reference pattern is used for the determination of the peak position in the broadened } \\
\text { pattern. There is no attempt made to determine } 2 \theta \text { of any peak from a broadened } \\
\text { pattern. }\end{array}$ \\
\hline 6 & $\begin{array}{l}\text { The estimated full width at half maximum (FWHM) in degrees } 2 \theta \text { of the reference } \\
\text { profile. If } 0.0 \text { is supplied then the FWHM will be estimated by the program. } \\
\text { Starting with this value, it may be refined by least-squares. The reason for } \\
\text { permitting one to supply this estimate is to allow one to deal with overlapped peaks. } \\
\text { When the reflections are not fully resolved, one must intervene with an estimate of } \\
\text { the FWHM. The algorithm for estimating FWHM for overlapped peaks is not able } \\
\text { to cope. }\end{array}$ \\
\hline 7 & $\begin{array}{l}\text { The estimated FWHM for the broadened peak. The same restrictions apply as in } \\
\text { field } 6 .\end{array}$ \\
\hline 8 & $\begin{array}{l}\text { Shape parameter of the left side of the reference profile. If } 0.0 \text { is supplied, the } \\
\text { default for all the starting values of the shape parameters is } 1.00 \text {. This assumes that } \\
\text { the shape of the input profile is nearly "Cauchy." When the profile is to be kept } \\
\text { symmetrical, it applies to the whole profile. }\end{array}$ \\
\hline 9 & $\begin{array}{l}\text { Shape parameter for the right side of the reference profile. Ignored for symmetrical } \\
\text { profiles. }\end{array}$ \\
\hline 10 & $\begin{array}{l}\text { Shape parameter for the left side of the broadened profile. If symmetrical, it applies } \\
\text { to the whole profile. }\end{array}$ \\
\hline 11 & $\begin{array}{l}\text { Shape parameter for the right side of the broadened profile. Ignored for symmetrical } \\
\text { profiles. }\end{array}$ \\
\hline 12 & $\begin{array}{l}0 / 1 \text { for do/do not place the filtered, separated profile in the } . \mathrm{DL} \text { output file. When } \\
1 \text {, the peak is treated as an impurity and discarded. }\end{array}$ \\
\hline
\end{tabular}




\section{SECOND LINE CONCERNING A REFLECTION}

In this line the least-squares refinement "switches" are supplied as $-1 / 0 / 1$ for program default/do not/do refine the named parameter. The use of the -1 to set defaults is complicated by the restrictions engendered by the chosen profile-fitting function. It may be necessary to make more than one run to determine which parameters should be allowed to refine for the problem at hand. Of course, some switches are automatically deactivated by choices specified in the previous reflection line.

\begin{tabular}{|l|l|}
\hline Field & Contents \\
\hline 1 & 'SIG_PARM_REF' \\
\hline 2 & 0/1 do not/do refine $2 \theta$ position of the reflection profile. \\
\hline 3 & $0 / 1$ do not/do refine the intensity scale of the reflection profile. \\
\hline 4 & $0 / 1$ do not/do refine the FWHM in the symmetrical mode. \\
\hline 5 & $0 / 1$ do not/do refine left side FWHM in split function mode. \\
\hline 6 & 0/1 do not/do refine right side FWHM in split function mode. \\
\hline 7 & 0/1 do not/do refine shape parameter in symmetrical mode. \\
\hline 8 & 0/1 do not/do refine left shape parameter in split function mode. \\
\hline 9 & 0/1 do not/do refine right shape parameter in split function mode. \\
\hline
\end{tabular}

\section{THIRD LINE CONCERNING A REFLECTION}

The 'NUM_ERR_GENR' line is used to prepare additional profiles which may be used to estimate errors in the size and strain parameters determined through the use of program CRYSIZ. The line will have eight numbers, one for each of the possible parameters in the leastsquares fitting process. These numbers are the multipliers of the estimated standard deviation in the least-squares parameters. The product $n_{i}{ }^{*} \sigma_{i}$ which results is used to change the value of the $i$ th fitting parameters. The set of new values is then used to generate a profile distorted by this "offset." This profile may then be used in place of the least squares profile to estimate the size and strain which is different by the multiple given in this line. The size and strain derived from the patterns which have been "distorted" by the application of the standard deviations derived for 
the least-squares will give a numerical approximation to the limits of error on the crystallite size and strain parameters determined in CRYSIZ.

This line is ignored or used depending upon the signal given in field 10 of the wavelength and general refinement control line. A NUM_ERR_GENR line must, however, always be included in the XIN file. The number supplied in each field is the multiple of the standard deviation of the corresponding variable in the previous line. A value between 0.0 and 3.0 is recommended. Negative values may be used. The fields are for the same parameters defined in the 'SIG_PARM_GENR' line.

\section{WINDOWS, REFLECTIONS, AND INPUT DATA ORDER - A REMINDER}

For each window in $2 \theta$ present on the diffractometer data file, the four types of lines, 'REGIN_2_THETA', 'HKL_2THT_SHP', 'SIG_PARM_REF', and 'NUM_ERR_GENR,' must be present. Moreover, if there is more than one profile in the window to be fitted, the last three of these lines must be repeated following the defining 'REGIN_2_THETA' line for each reflection in that window. All the lines must be given in the same order as the measurements in the diffractometer data file. This order is usually as increasing $2 \theta$.

\section{LINE TO TERMINATE A .XIN FILE}

\begin{tabular}{|l|l|}
\hline Field & Contents \\
\hline 1 & 'REGIN_2_THET' \\
\hline 2 & -1 \\
\hline
\end{tabular}


EXAMPLE OF A.XIN FILE

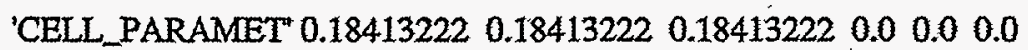

'WAV_LEN_REFN' -1. - 1. -1. -1, N' 00.00 .00

'REGIN_2_THET' 12001101300.011100 'Y'

$\begin{array}{lllllllllll} & \text { 'HKL_2THT_SHP' } 11 & 1 & 28.443 & 0.0 & 0.0 & 0.0 & 0.0 & 0.0 & 0.0 & 0\end{array}$

'SIG_PARM_REF' 11110010100

'NUM_ERR_GENR' 0000000000

'REGIN_2_THET' $12001101300.011100 . \mathrm{Y}$

'HKL_2THT_SHP' $220047.304 \quad 0.0 \quad 0.0 \quad 0.0 \quad 0.0 \quad 0.0 \quad 0.0 \quad 0$

'SIG_PARM_REF' 111100100

NUM_ERR_GENR' 00000000000

'REGIN_2_THET" 1201101300.01100 "Y*

'HKL_2THT_SHP' $311156.122 \quad 0.0 \quad 0.0 \quad 0.0 \quad 0.0 \quad 0.0 \quad 0.00$

'SIG_PARM_REF' 11100100

'NUM_ERR_GENR' 00.0000000

REGIN_2_THET 12001101300.0111000 '

$\begin{array}{llllllllll} & \text { 'HKL_2THT_SHP' } 42 & 28.029 & 0.0 & 0.0 & 0.0 & 0.0 & 0.0 & 0.0 & 0\end{array}$

'SIG_PARM_REF' 11110001.00

NUM_ERR_GENR' 0000000000

REGIN_2_THET $12.01101 .300 .0111000^{\prime} \mathrm{Y}$

HKI_2THT_SHP' $6220127.547 \quad 0.0 \quad 0.0 \quad 0.0 \quad 0.0 \quad 0.0 \quad 0.0 \quad 0$

'SIG_PARM_REF 1111.00100

NUM_ERR_GENR' 0000000000

'REGIN_2_THET -1 


\section{REFERENCES}

1. J. M. Stewart, Y. Zhang, C. R. Hubbard, B. Morosin, and E. L. Venturini, XRAYL: A New Powder Diffraction Profile Refinement Program, NIST-IR 88-3850, Gaithersburg, Md., 1988.

2. D. Taupin, "Automatic Peak Determination in X-ray Powder Patterns," J. Appl. Crystallogr. 6, 266 (1973).

3. W. Parrish, T. C. Huang, and G. L. Ayres, "Profile Fitting: A Powerful Method of Computer X-ray Instrumentation and Analysis," Trans. Am. Crystallogr. Assoc. 12, 65 (1976).

4. J. Mignot and D. Rondot, "Application du Lissage des Raies de Diffraction des Rayons Xa la Separation du Double $\mathrm{K} \alpha_{1}, \alpha_{2}$," J. Appl. Crystall. 9, 460 (1976).

5. M. M. Hall, Jr., V. G. Veeraraghavan, H. Rubin, and P. G. Winchell, "The Approximation of Symmetric X-ray Peaks by Pearson Type VII Distributions," J. Appl. Crystall. 10, 66 (1977).

6. Th. H. De Keijser, J. I. Langford, E. J. Mittermijer, and A. B. P. Vogels, "Use of the Voigt Function in a Single Line Method for Analysis of X-ray Diffraction Line Broadening," J. Appl. Crystallogr. 15, 308 (1982).

7. H. M. Rietveld, "Line Profiles of Neutron Powder-Diffraction Peaks for Structure Refinement," Acta Crystallogr. 22, 151 (1967).

8. H. M. Rietveld, "A Profile Refinement Method for Nuclear and Magnetic Structures," J. Appl. Crystallogr. 2, 65 (1967).

9. G. Caliotti, A. Paoletti, and F. P. Ricci, "Choice of Collimators for a Crystal Spectrometer for Neutron Diffraction," Nucl. Instrum. 3, 223 (1958).

10. C. Greaves, "Rietveld Analysis of Powder Neutron Diffraction Data Displaying Anisotropic Crystallite Size Broadening," J. Appl. Crystallogr. 18, 48 (1985).

11. H. P. Klug and L. E. Alexander, X-Ray Diffraction Procedures, 2d ed., John Wiley and Sons, New York, 1974.

12. Y. Zhang, "Advances in X-ray Powder Diffraction Profile Analysis and its Application in Ceramic Material Studies," Ph.D. Thesis, University of Maryland, College Park, Md., 1988.

13. Y. Zhang, J. M. Stewart, B. Morosin, R. A. Graham, and C. R. Hubbard, "X-Ray line broadening study on shock-modified hematite," p. 287 in Advances in X-Ray Analysis, Vol 31, ed. C. S. Barrett et. al., Plenum Pub., New York, 1988.

14. National Bureau of Standards, Guide to Available Mathematical Software, NBSIR842824, Gaithersburg, Md., 1984. 


\section{APPENDIX A - Format of the <identity >.DA and <identity >.IDL files}

The structure of the input.DA files read by program XRAYL is as shown below. These files contain, in FORTRAN-FORMATTED ASCII, the intensity measurements from regions of $2 \theta$, "windows," in steps of $2 \theta$ taken from the diffractometer. The format of these records is identical to the format shown below for the .IDL files. The distinction is that the region of $2 \theta$ in a.DA file specifies a window which may contain up to five reflections. In .DA files the reflection indices are ignored since it is assumed that there may be more than one reflection per window. These may be both reflections of the phase under study and of impurities. Therefore, specified reflection information in a.DA file is ignored in favor of the reflection specifications for the window given to XRAYL interactively or by means of the .XIN input file which is described in the body of this document. The structure of the output .IDL, .IDM, and .IDP files written by the program XRAYL is as follows. These files contain, in ASCII, the intensity measurements at steps in $2 \theta$ for individual, separated reflections. The same format is used for both reference and broadened patterns which are distinguished by the <identity > portion of the file name. Some operating systems may restrict <identity > to be fewer than 11 characters. The pattern of records shown below repeats for each reflection or window of the sample. The end of all reflections is marked by an end-of-file.

It is conventional to place data in these files in windows of $2 \theta$ with up to five peaks per window. Whatever order is used for the windows in the .DA file, that order must be used in setting up the .XIN instruction file. A.DA file may have any number of windows in it. 


\begin{tabular}{|l|l|l|}
\hline Record & Format & Contents \\
\hline 1 & A53 & $\begin{array}{l}\text { Title; up to the first } 11 \text { characters may be the } \\
\text { <identity } \text { used to identify the files of the } \\
\text { compound }\end{array}$ \\
\hline 1 & A19 & $\begin{array}{l}\text { Time/date as bhh:mm:ssbdd/MMM/yy where "b" } \\
\text { represents a blank space }\end{array}$ \\
\hline 2 & I4 & h index of reflection \\
\hline 2 & I4 & $\mathrm{k}$ \\
\hline 2 & I4 & l \\
\hline 2 & I4 & $\begin{array}{l}\text { Number of records of type 3, intensity data, } \\
\text { NREC, which must be }>15 \text { and }<1023\end{array}$ \\
\hline 2 & F10.2 & Counting time per intensity point \\
\hline 2 & F10.4 & Beginning $2 \theta$ for intensity measurements \\
\hline 2 & F10.4 & Ending $2 \theta$ for intensity measurements \\
\hline 2 & F10.4 & $2 \theta$ step size, lower limit $0.001^{\circ}$ \\
\hline 2 & F10.6 & Wave length of $\mathrm{K} \alpha_{1}$ used for measurement \\
\hline 3 through & F10.2 & Intensity at measured point \\
\hline $2+$ NREC & &
\end{tabular}




\section{APPENDIX B - Auxiliary programs to support XRAYL}

Three short programs exist to aid in checking and using XRAYL. The first two, POWTES and POWTESTW, will generate .DA (raw data) files with ideal Gaussian profiles. POWTES generates single lines which are specified by using the program interactively. POWTESTW generates a pair of overlapping lines. To supply the necessary data, one must have a test substance in mind. An example is Si measured with copper radiation for which there are five prominent lines. The cell is cubic with $\mathrm{a}^{*}=0.18413222$ per Angstrom.

Reflection $2 \theta$

$111 \quad 28.443$

$220 \quad 47.304$

$331 \quad 56.122$

$422 \quad 88.029$

$620 \quad 127.547$

Interaction will require the following additional information:

1. The output file name; <identity>.DA (e.g., TEST.DA).

2. The title consisting of up to 53 characters; the first 6 characters of the string must be <identity> (e.g., "TEST").

3. The number of points in the $2 \theta$ scan; more than 15 , less than 1023.

4. The $2 \theta$ step size; less than 1 , greater than or equal to 0.001 degrees.

5. Backgound counts; 0.0 to 100.0 .

6. Count time for each intensity measurement; between 1 and $1000 \mathrm{~s}$.

Then $7,8,9$, and 10 are entered repeatedly until stopped by a response of $n$ to the "continue?" prompt.

7. $h, k$, and $l$ of the line.

8. $2 \theta$ maximum for the line. For POWTESTW also the offset to the overlapping line.

9. The full width at half maximum (FWHM). For POWTESTW also the FWHM of the overlapping line. 
10. Intensity scale for line maximum; 1.0 to 1000.0. POWTESTW also reqires this.

11. Response of $y / n$ to go back to step 7 or quit data entry.

These two programs serve to give ideal Gaussian data with no statistical errors to use in checking XRAYL and to allow practice with the nature of the program XRAYL before applying it to "real" data.

The third program, POWCON, requests items $1,2,6,7,8$, and the name of the file containing the raw data. As distributed the structure of this diffractometer file is assumed to be simply sequential ASCII records of FORTRAN FORMAT (1X,F6.2,F9.0) consisting of $2 \theta$, in ascending order with equal steps, and intensity values. The program is short and may be easily modified to other diffractometer data formats. From the survey of the whole file, the rest of the information needed to form a.DA file is calculated, and the mass of intensity data is written out to the output file.

A more complicated, direct access file of the type created by SCINTAG DMS2000 software may be translated using the program RDCON.

The two programs POWTRY and POWWID, based on POWTES, may be used to generate test data with controlled amounts of broadening. The programs are run interactively and by appropriate responses to prompts will permit the generation of patterns with specified size and strain parameters. The generated patterns may then be used to test XRAYL and CRYSIZ. The main object of the test will be to see the results of the CRYSIZ analysis of the pseudo data. The programs are commented and described more fully in Appendix C of the CRYSIZ documentation. If more details are wanted, comments in the FORTRAN source code may be examined. 


\section{APPENDIX C - History of the authorship of programs XRAYL, POWTES, and CRYSIZ}

These programs were first proposed in the summer of 1984 by Dr. Bruno Morosin of Sandia National Laboratories. In the summers of 1984 and 1985, the initial coding was undertaken, at Sandia, by Professor James M. Stewart of the University of Maryland in College Park. In 1986, Dr. Camden Hubbard, then at the National Institute for Science and Technology (formerly The National Bureau of Standards), undertook to advise Dr. Yuming Zhang, then a graduate student, and Professor Stewart in combining the original Sandia codes with codes that Dr. Hubbard had written. These codes, written by Hubbard, Stewart, Morosin, Zhang, and Venturini, are documented in NBS IR-88-3850. The present code is a modification and enhancement of this long, collaborative effort. Many details and examples of the use of the programs and the extensive references to the methods coded in them can be found in Dr. Zhang's 1988 thesis, "Advances in X-ray Powder Diffraction Analysis and its Application in Ceramic Material Studies," a dissertation submitted to the faculty of the graduate school of The University of Maryland.

XRAYL serves to separate overlapped powder profiles by fitting with analytical functions, while CRYSIZ combines the classic plotting methods and the Warren-Averbach methods for the determination of crystallite size and strain. POWTES, POWTE2, POWCON, and RDCON were written by Hubbard and Stewart as an aid to testing and for converting data to the required input format. 



\section{APPENDIX D - Symbolic "decks" and their implementation}

The following symbolic decks are supplied on one 3.5-in. IBM, FAT format diskette in Appendix F:

POWCON.FOR (a utility program for converting raw data files to type .DA).

POWLAP.FOR (a utility program for generating overlapping line tests from input data).

POWTES.FOR (a utility program for generating single Gaussian lines to test XRAYL).

POWTESTW.FOR (a utility program for generating double lines to test XRAYL).

POWTRY.FOR (a utility program to generate POWWID test data three trials per run).

POWWID.FOR (a utility program to convolute Gaussian data to test CRYSIZ).

RDCON.FOR (a program to convert SCINTAG.RD files to .DA files required by XRAYL).

TAGFOR.FOR (a utility for sequencing FORTRAN programs in cols. 73-80).

TIMDAT.FOR (a machine-specific time/date subroutine; not needed for VAX).

XRAYL96.FOR (the main program and the first half of the XRAYL subroutines).

XRAYLP2.FOR (the rest of the XRAYL subroutines).

XRAYLCOM.FOR (the common arrays to be automatically included in XRAYL subroutines).

SLATEC.FOR (the machine independent matrix manipulation and least-squares subroutines).

SLASPC.FOR (the machine- and operating system-specific parts of SLATEC).

The preponderance of the FORTRAN 77 code is completely "transportable." However, before attempting to compile these programs, three machine-specific aspects of the FORTRAN statements must be checked and set for local compiler/hardware conventions. The first is the structure of the OPEN statements; search on "OPEN(" to locate them in every symbolic deck. Various vendors have different conventions for the specification of file characteristics. The distributed disk is set for those used by an IBM or compatible personal computer (PC).

The second modification must be made if a machine other than a PC is being used. These changes must be made in the SLASPC.FOR routines. These routines are the Slatec routines which set up register characteristics. The code is mostly comments showing the statements necessary for various hardware/software. If changing from a PC, the $\mathrm{PC}$ active code must by made inoperable by placing a " $\mathrm{C}$ " in column one and the appropriate statements for the target 
machine made active by removing the " $\mathrm{C}$ " from column one on the lines required by the target machine.

The third modification which may be necessary is in the TIMDAT.FOR subroutines for the setting of the time and date. These functions are very important for identifying runs. Each computer vendor will provide different system subroutines for this purpose. In the programs, there are calls to TIMDAT.FOR which then calls the time and date subroutines of the operating system. All the other routines call TIMDAT.FOR to get the time and date in the appropriate format. The subroutines become null on a microVAX running under VMS since the conventions used mimic that machine. The object module of TIMDAT will have to be linked to every one of the programs listed above. In the case of these time and date subroutines, it is possible to simply "dummy" them. However, even if this is done to get started quickly, it is inadvisable to continue operating the programs in this mode if one is to avoid confusion with respect to the files which are generated by the programs when they are used for production runs.

The program XRAYL is supplied in five files as shown above. XRAYL96.FOR, XRAYLP2.FOR, SLATEC.FOR, and SLASPC.FOR are the symbolic decks.

XRAYLCOM.FOR is the file of COMMON statements. It must be available during compilation to satisfy the FORTRAN INCLUDE statements of the symbolic programs. These statements cause automatic loading of the common arrays from the file XRAYLCOM.FOR into each subroutine that requires them.

Once a suitable directory (path) has been set up on the target machine, and the files loaded into it and edited to change any of the statements described above, the programs may be compiled and linked according to local custom. Testing may be carried out using the supplied data files or by generating ideal tests using any of the programs such as POWTRY.FOR. 


\section{APPENDIX E - Example runs for testing XRAYL}

The main body of this appendix is not printed in this document, rather it is stored on the "EXAMPLES" diskette containing test data and test output that is distributed with this document. On that diskette there is a collection of files, both input and output, which may be used to understand and test XRAYL. The contents of the files are summarized in this appendix along with printed sample plots prepared from the <identity>.XEX files produced by XRAYL. The plots shown here were prepared using the program KaleidaGraph ${ }^{\mathrm{TM}}$ purchased from Synergy Software, Reading, PA 19606-2049. This program and others like it may be used to produce plots from the data produced by XRAYL. No details of the use of KaleidaGraph ${ }^{\text {TM }}$ will be shown in this document. XRAYL produces a file of type .XEX in which the plots requested in the .XIN file are placed as labeled tables of $\mathrm{X}$ and $\mathrm{Y}$ coordinates. A local line editor can be used to extract plot data of interest. Each plot is marked with a line: "BEGIN PLOT " for searching purposes. The graphics program will have a facility for "importing" the separated file and editing the description of the $\mathrm{X}$ and $\mathrm{Y}$ data. Once the data are imported, the rules of the graphics progam must be followed to make the plots.

Table E.1 lays out the purpose of the files on the disk, where they are created, and where they are used. Table E.1 is set out in order of program use to illustrate a sequence of program and file utilization. In Table E.1 the example presented is that of a pair of overlapped profiles generated for the purpose of illustrating and checking the use of XRAYL. The <identity> shown for each file is the one used on the distribution disk. These <identity $>$ labels all use the letters "SEP" in order to distinguish this set of examples. There are other tests on the diskette using other mnemonics which are described in Appendix C of the CRYSIZ document.

KaleidaGraph ${ }^{\mathrm{TM}}$ produces files of type <identity>.QDA, .QPC, and .WMF among others which are not used in these examples. The .QDA files are the input data reformatted from the .TXT files. The .QPC files are the binary images of the final plots. The. WMF files are bit-maps suitable for importing into document processors. The plots shown below were taken directly into this document from the WMF files. 
Table E.1. Purpose of files on disk, where they are created, and where they are used

\begin{tabular}{|c|c|c|c|}
\hline Program & Purpose & Input files & Output files \\
\hline POWTES & Generate test Gaussian profiles & None & $\begin{array}{l}\text { SEPRI.DA } \\
\text { SEPBI.DA }\end{array}$ \\
\hline POWLAP & Generate overlapped test profiles & $\begin{array}{l}\text { SEPRI.DA } \\
\text { SEPBI.DA }\end{array}$ & $\begin{array}{l}\text { SEPR.DA } \\
\text { SEPB.DA }\end{array}$ \\
\hline XRAYL & $\begin{array}{l}\text { Separate overlapped profiles and } \\
\text { fit them to an analytical function }\end{array}$ & $\begin{array}{l}\text { SEP.XIN } \\
\text { SEPR.DA } \\
\text { SEPB.DA }\end{array}$ & $\begin{array}{l}\text { SEPR.IDL } \\
\text { SEPB.IDL } \\
\text { SEPRSEPB.XPN } \\
\text { SEPRSEPB.XPL } \\
\text { SEPRSEPB.FIT } \\
\text { SEPRSEPB.XEX }\end{array}$ \\
\hline Local line editor & $\begin{array}{l}\text { Separate out the data sets for } \\
\text { plotting }\end{array}$ & SEPRSEPB.XEX & $\begin{array}{l}\text { *IN.TXT } \\
\text { *OUT.TXT } \\
\text { *DIF.TXT } \\
\text { *1.TXT } \\
\text { *2.TXT } \\
\text { *Stands for SEPR and } \\
\text { SEPB (10 files) }\end{array}$ \\
\hline KaleidaGraph $^{\mathrm{TM}}$ & $\begin{array}{l}\text { Produce high-quality plots for } \\
\text { publication }\end{array}$ & $\begin{array}{l}\text { *IN.TXT } \\
\text { *OUT.TXT } \\
\text { *DIF.TXT } \\
\text { *1.TXT } \\
\text { *2.TXT } \\
\text { *Stands for SEPR and } \\
\text { SEPB (10 files) }\end{array}$ & $\begin{array}{l}\text { *.QDA } \\
\text { *.QPC } \\
\text { *.WMF } \\
\text { *R.QDA } \\
\text { *R.QPC } \\
\text { *R.WMF } \\
\text { *Stands for SEPR and } \\
\text { SEPB (12 files) } \\
\end{array}$ \\
\hline
\end{tabular}

The formats and contents of all files except those of type .TXT, .QPC, .QDA, and .WMF are given elsewhere in this document.

Figure E.1 shows, for the reference profile, the raw data from POWLAP, the fitted data from XRAYL, and the difference between the two profiles superimposed on one plot. Figure E.2 shows the same plot for the broadened data. Figure E.3 shows the two reference profiles extracted by XRAYL superimposed on one plot. The important thing is that in the .DA file there was just one record, just as it might have come from the diffractometer. In the .IDL file the two profiles are in separate records, one of which could be ignored if that were appropriate. Figure E. 4 is the broadened profiles plotted as in Figure E.3.

Figures E.5 and E. 6 are plots of real data taken for a shock modified sample of zirconia. The files containing these data are of the group ZR $5 * * *$ on the examples diskette. 


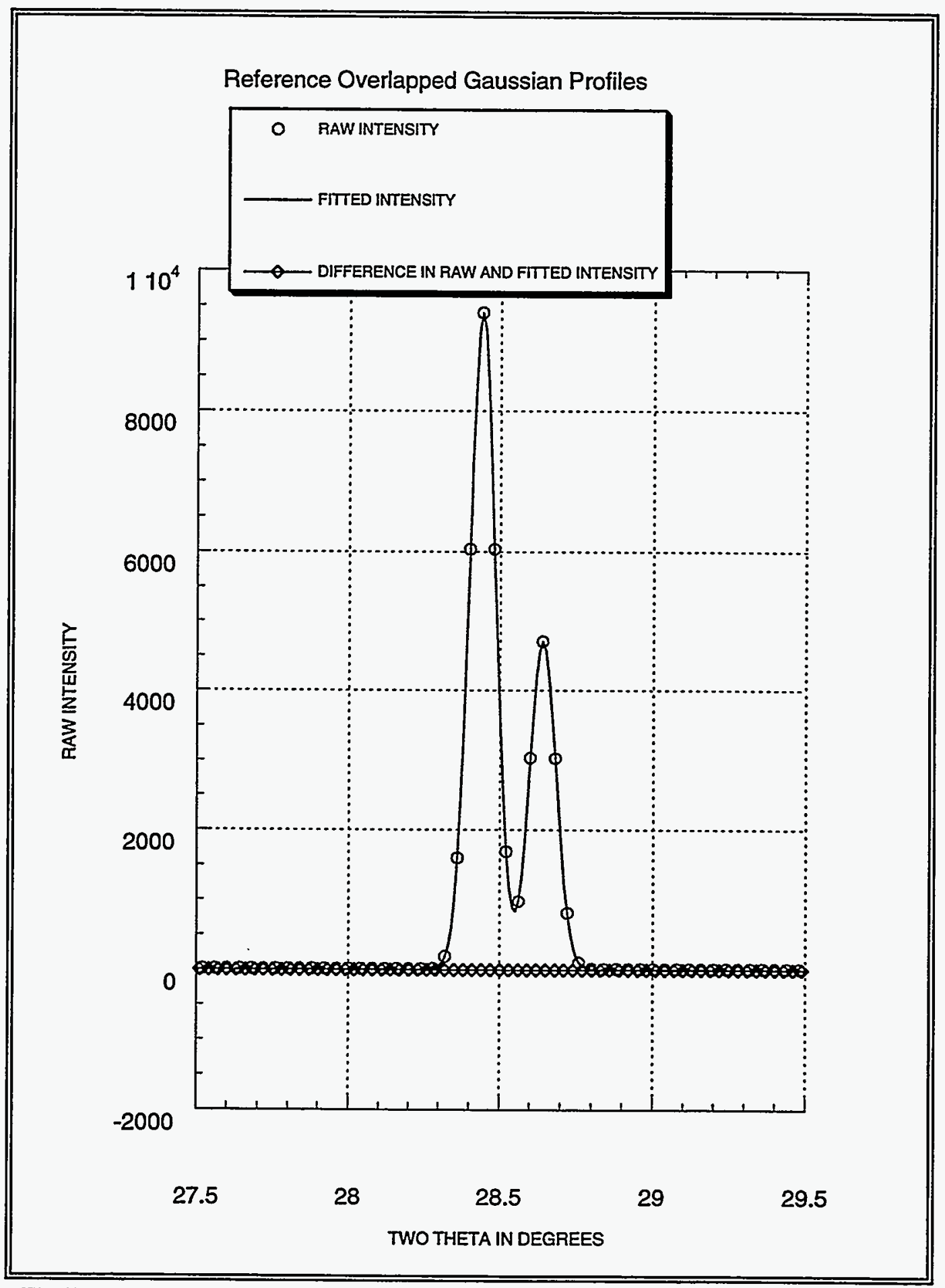

Fig. E.1. Raw data from POWLAP, fitted data from XRAYL, and difference in raw and fitted intensity. 


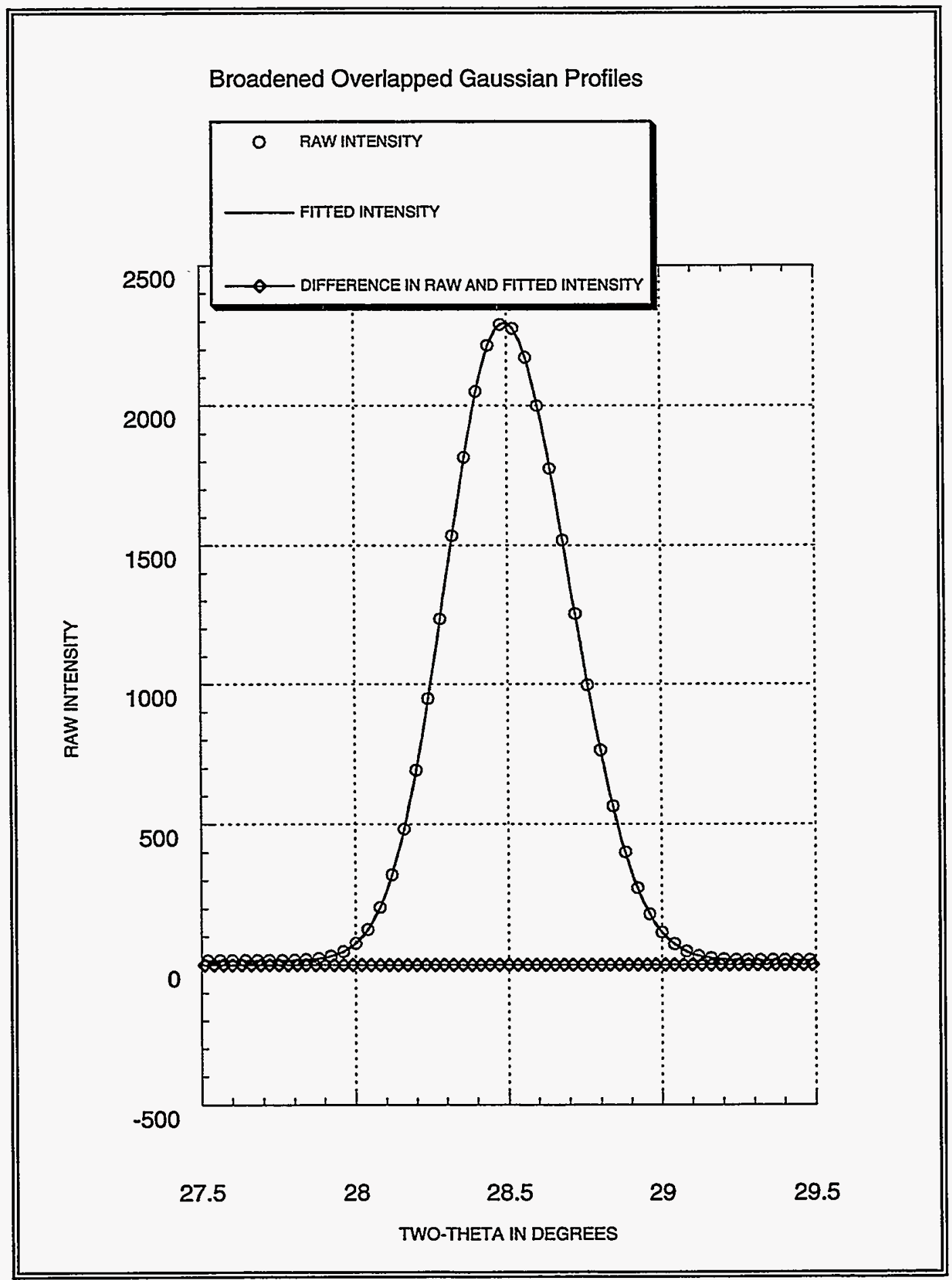

Fig. E.2. Same plot as for Fig. E.1, but for the broadened data. 


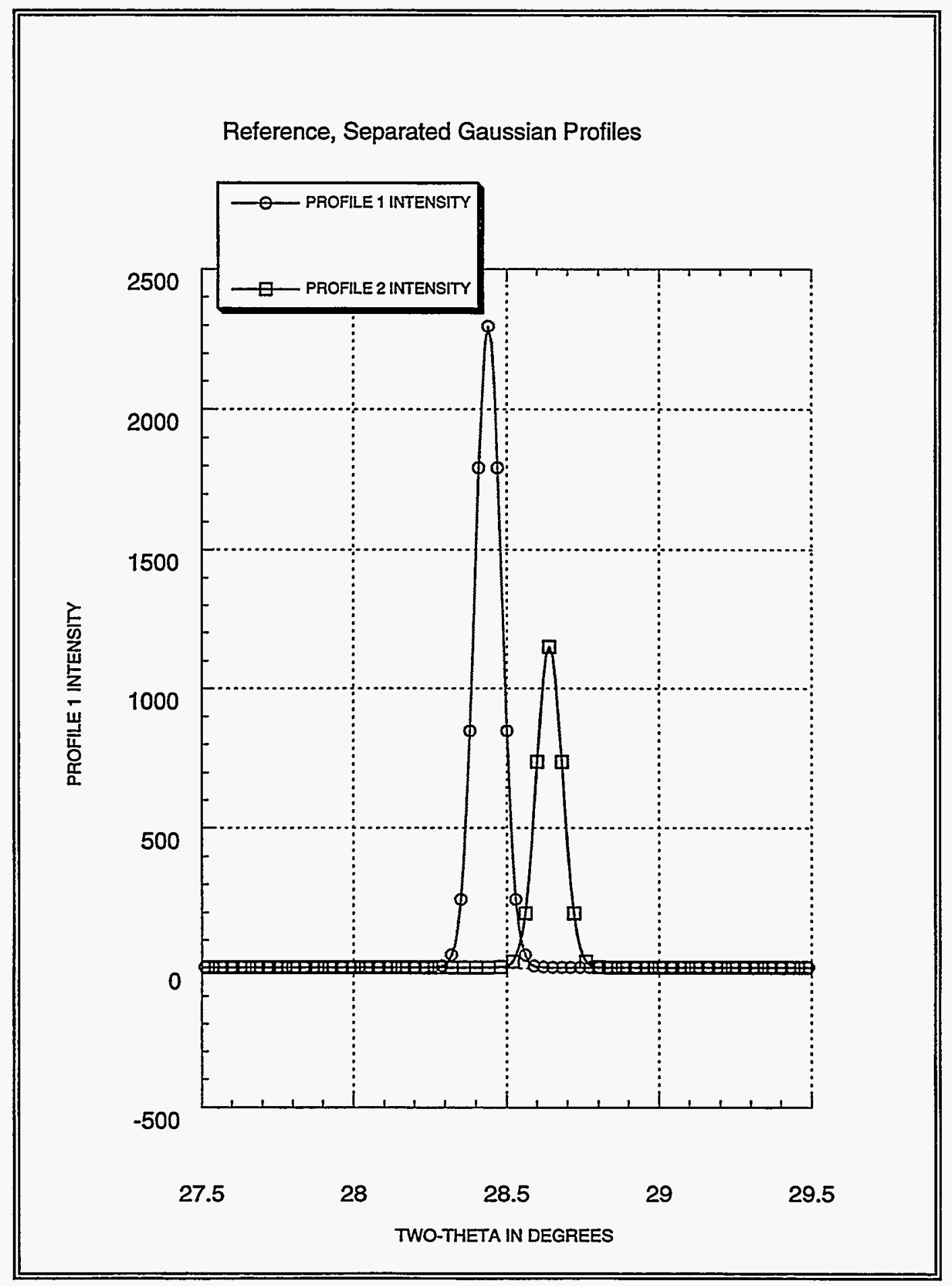

Fig. E.3. Two reference profiles extracted by XRAYL, superimposed on one plot. 


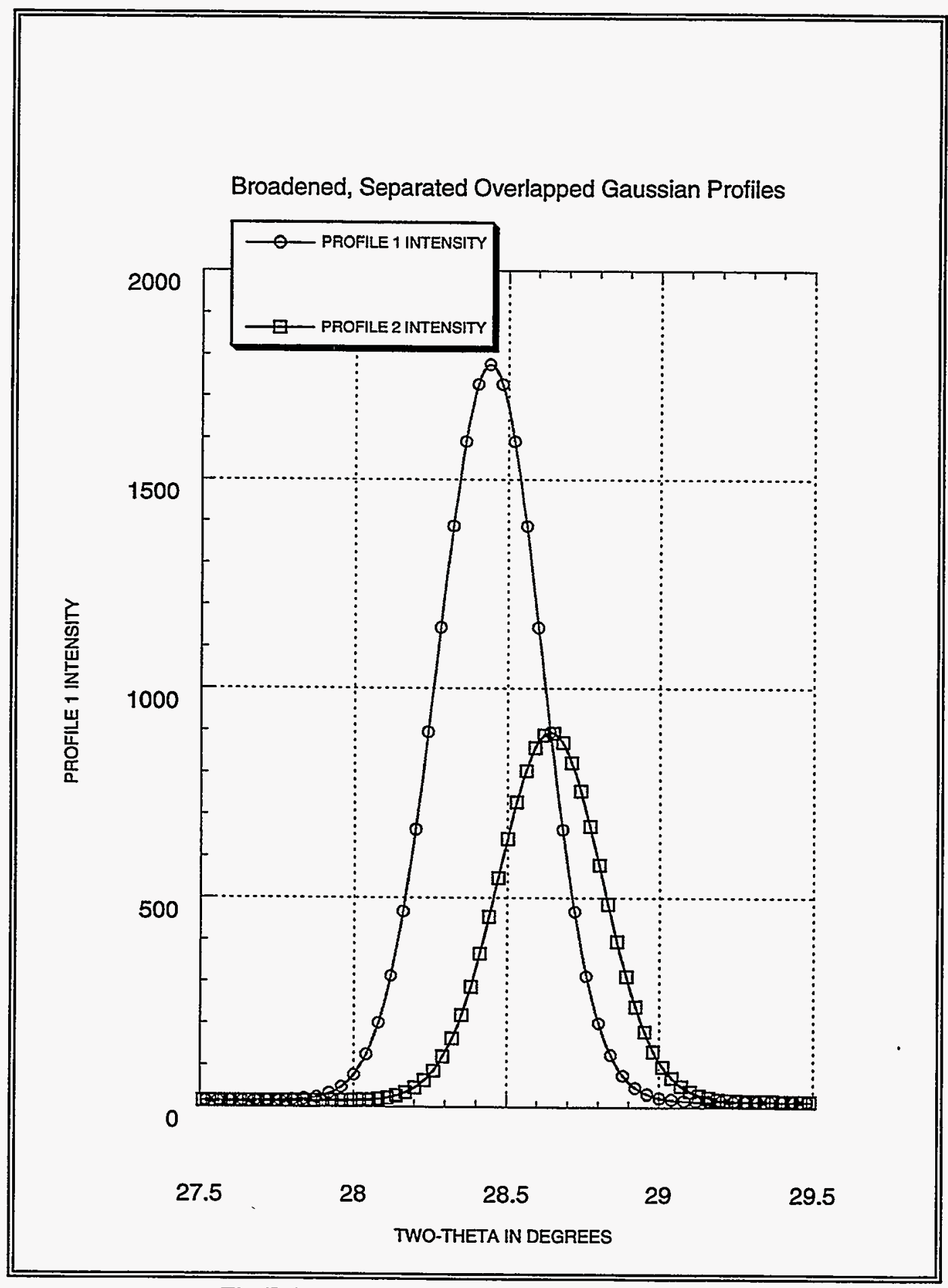

Fig. E.4. Broadened profiles plotted as in Fig. E.3. 


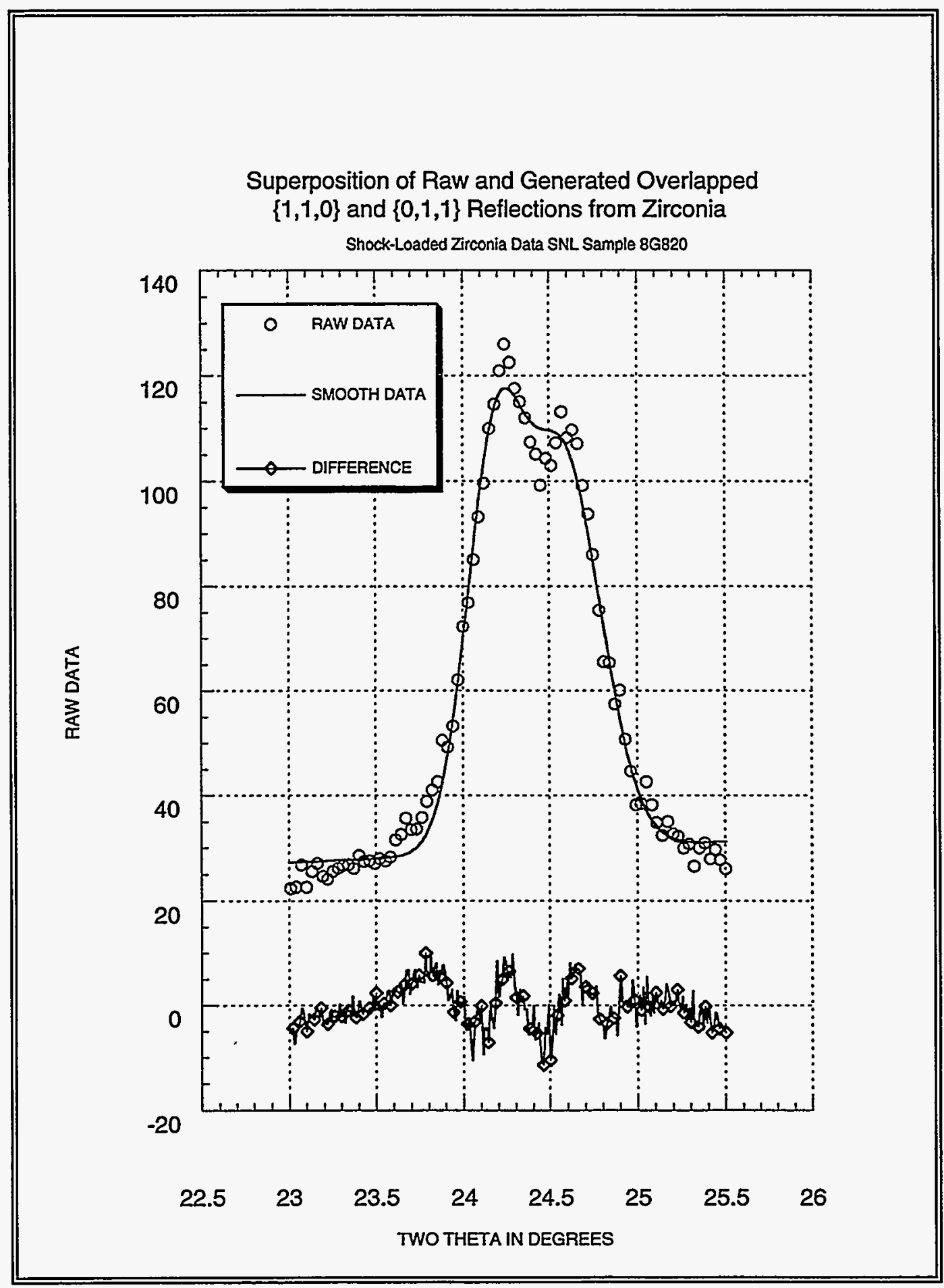

Fig. E.5. Plot of real data taken for shock-modified sample of zirconia. 


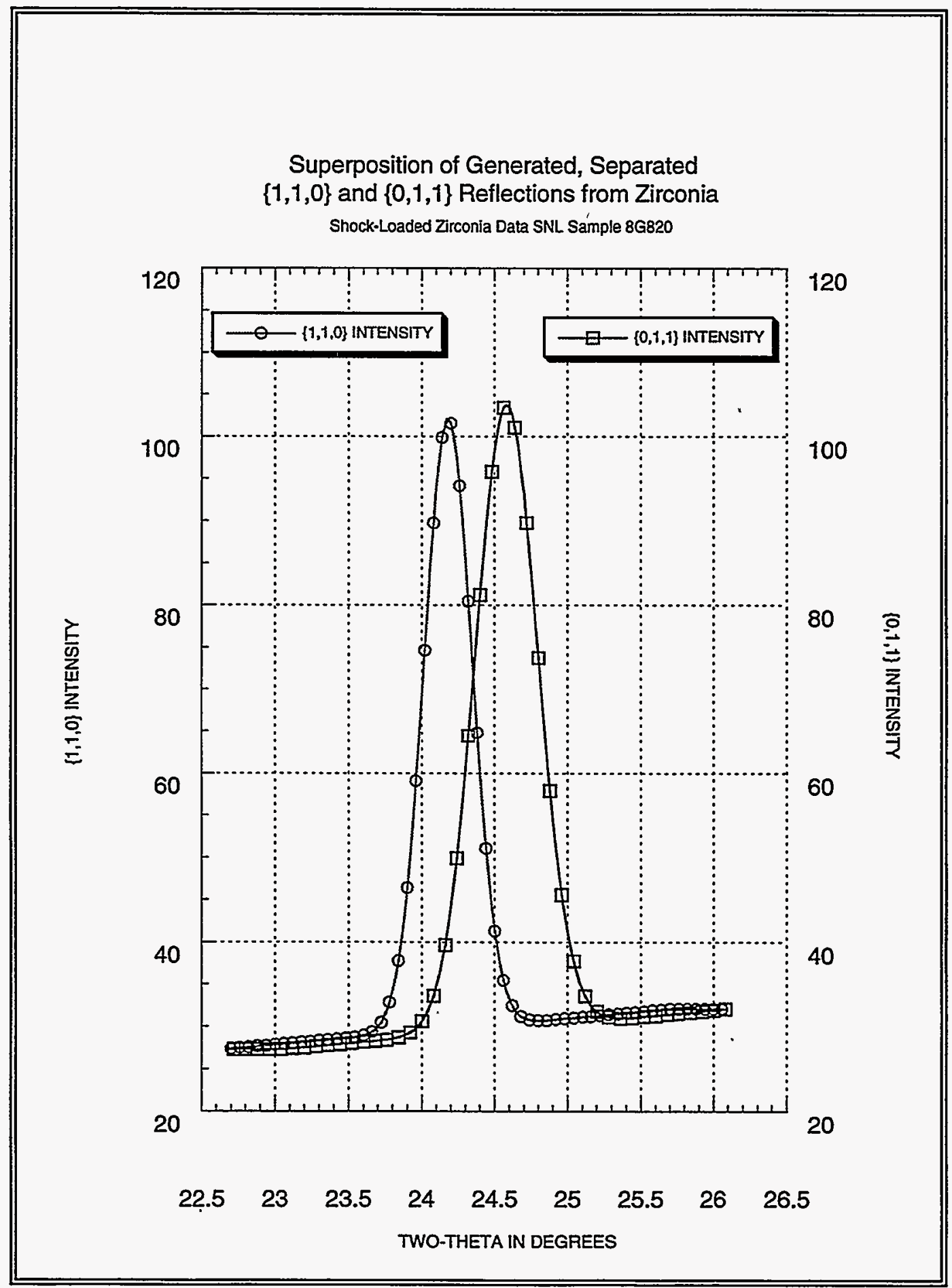

Fig. E.6. Plot of XRAYL profiles of real data shown in Fig. E.5. 


\section{APPENDIX F- Source code and example diskettes}

The diskettes contain:

The volume label in drive A is XRAYL.

Directory of A:I

XRAYL96.FOR XRAYLCOM.FOR XRAYLP2.FOR SLATEC.FOR SLASPC.FOR TIMDAT.FOR POWCON.FOR POWTESTW.FOR POWLAP.FOR POWWID.FOR POWTRY.FOR POWTES.FOR RDCON.FOR TAGFOR.FOR XRAYL.LST 15 file(s) 1058111 bytes used 389632 bytes free

The volume label in drive $A$ is XRAYLSEPTES.

Directory of A:I

\begin{tabular}{lllll} 
SEP.XIN & SEPR.DA & SEPB.DA & SEPRIN.TXT & SEPROUT.TXT \\
SEPR.ID & SEPB.IL & SEPR.FIT & SEPRSEPB.XPN & SEPRSEPB.XEX \\
SEPRSEPB.XPL & SEPB2.TXT & SEPB1.TXT & SEPBR.TXT & SEPBR.QPC \\
SEPBR.QDA & SEPB2.QPC & SEPB2.QDA & SEPBR1.QDA & SEP1_2.QPC \\
SEPBR.WMF & SEPRDIF.TXT & SEPBIN.TXT SEPBOUT.TXT & SEPBDIF.TXT \\
SEPRR1.TXT & SEPRR2.TXT & SEPBR1.TXT SEPBR2.TXT & SEPR.QPC \\
SEPR.QDA & SEPB.QPC & SEPB.QDA & SEPRR.QPC & SEPRR.QDA \\
SEPB.WMF & SEPR.WMF & SEPRR.WMF SEDIR.LST & \\
\multicolumn{1}{c}{ 39 file(s) } & 1034048 bytes used & & \\
& 784269312 bytes free & &
\end{tabular}




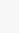


ORNL/TM-13272

\section{INTERNAL DISTRIBUTION}

1-2. Central Research Library

3. Document Reference Section

4-5. Laboratory Records Department

6. Laboratory Records Department - RC

7. ORNL Patent Section

8-10. M\&C Records Office
11-20. C. R. Hubbard

21. S. T. Misture

22. A. E. Pasto

23. E. A. Payzant

24. T. R. Watkins

\section{EXTERNAL DISTRIBUTION}

25. OHIO STATE UNIVERSITY, 2041 College Avenue, Columbus, OH 43210-1179

R. L. Snyder

26-35. SANDIA NATIONAL LABORATORIES, P.O. Box 1421, Albuquerque, NM 87185-1421

B. Morosin

36-38. JAMES M. STEWART, P.O. Box 472, McConnellsburg, PA 17233-0472

39. DOE, OAK RIDGE OPERATIONS OFFICE, P.O. Box 2001, Oak Ridge, TN 37831-6269

Office of Assistant Manager for Energy Research and Development

40. DOE, OFFICE OF SCIENTIFIC AND TECHNICAL INFORMATION, P.O.BOX 62, Oak Ridge, TN 37831-0062 